\title{
Active surveillance of adverse drug reactions in children in five Italian paediatric wards ${ }^{*}$
}

\author{
Mariapina Gallo ${ }^{1}$, Antonio Clavenna ${ }^{2}$, Maurizio Bonati ${ }^{2}$, Paolo Siani ${ }^{3}$, Antonio Irpino ${ }^{4}$, \\ Francesco Rossi ${ }^{1}$, Annalisa Capuano ${ }^{1}$
}

${ }^{1}$ Department of Experimental Medicine, Section of Pharmacology "Leonardo Donatelli”, Center of Pharmacosurveillance and Pharmacoepidemiology, Faculty of Medicine and Surgery, Second University of Naples, Naples, Italy

${ }^{2}$ Laboratory for Mother and Child Health, Department of Public Health, Mario Negri Institute for Pharmacological Research, Milan, Italy

${ }^{3}$ Pediatric Department, AORN A. Santobono-Pausillipon Hospital, Naples, Italy

${ }^{4}$ Department of European and Mediterranean Studies, Faculty of Political Studies and Higher European Education Jean Monnet, Second University of Naples, Naples, Italy

Email: mapigal@inwind.it

Received 1 March 2012; revised 18 April 2012; accepted 26 April 2012

\section{ABSTRACT}

Adverse drug reactions (ADRs) are an important clinical problem and contribute significantly to mortality and morbidity. Scant data on the safety of drug use in children are usually available at the time of marketing authorization, due to the limited number of trials performed in the paediatric population. Few studies monitored the incidence of ADRs in Italian hospitalized children, that cannot be compared for methodological reasons. A 6-month prospective observational study was, therefore, conducted on the paediatric wards of five hospitals in the Campania Region, Italy. Data were collected on all patients admitted to the wards during the study period through a structured questionnaire administered to the mothers and through a hospital chart review. Of the 752 patients enrolled, $86.2 \%$ were exposed to one or more drugs during hospitalization. The therapeutic class most prescribed was systemic antibacterial agents (47\%). Six ADRs occurred during hospitalization (incidence $0.9 \%$; $95 \%$ CI $0.2 \%-1.7 \%$ ). In addition, one child was admitted to a hospital for an ADR. Five out of seven ADRs occurred in girls. The skin was the most affected organ. The medications implicated were amoxicillin, acyclovir, ibuprofen, ceftriaxone, paracetamol, and ranitidine. According to the $\mathrm{Na}$ ranjo probability criteria, six ADRs were probably, and one possibly, related to the suspected drug. In conclusion, this study reveals that ADRs may be under-reported in children hospitalized in the Campania Region. Consequently, healthcare personnel

\footnotetext{
"The authors are on behalf of APDR Regional Study Group: G. Basilicata, L. De Seta, B. Ianniello, M. L. Illiano, U. Maglione, C. Rafaniello S. Ruggiero, F. Saitta, L. Tarallo, G. Vetrano.
}

should be alert to the possibility of ADRs. More accurate reporting of ADRs in children would result in safer use of drugs in such patients.

Keywords: Child; Prospective Studies; Drug Therapy/Adverse Effects; Adverse Drug Reaction Reporting System; Hospital

\section{INTRODUCTION}

A crucial issue in drug therapy is the risk of adverse drug reactions (ADRs). ADRs are an important clinical problem and contribute significantly to mortality and morbidity $[1,2]$. They can result in diminished quality of life, a greater need for physician visits and hospitalizations, and even death in adults and children [3-5].

Before a new drug is marketed, clinical trials are generally conducted in adult patients and, only in a few instances, in children, although the situation is improving $[6,7]$. Pre-marketing trials are unable to detect the full range of ADRs that can occur both in adults and in the paediatric population. Therefore, data on the efficacy and tolerability of drugs and information regarding ADRs in children are often lacking. The spectrum of ADRs in children can differ from that manifested in adults in terms of frequency, nature, and severity. It is widely agreed that ADRs reported in adults do not always predict ADRs in children [8]. Anatomical differences in body proportions and age-related differences in body composition, and in enzymatic pathways and maturation, distinguish newborns, infants, and children from adults. Children have been shown to be more susceptible to particular toxic effects than adults [9]. Some ADRs are specific to the paediatric population because of the growth and development that children undergo (e.g. Reye's syn- 
drome with acetyl salicylic acid [10]). Other ADRs are more common in children (e.g. dystonia with metoclopramide [11]). Several risk factors may account for the severity and specificity of ADRs in children, namely, age-dependent changes in pharmacokinetics and pharmacodynamics.

Consequently, attention has begun to focus on ADRs in the paediatric population; several prospective studies indicate that ADRs in children are of great clinical relevance. A meta-analysis of eight prospective studies published in the 2001-2007 period estimated an incidence rate of ADRs among hospitalized children of $10.9 \%$ (95\% confidence interval $[\mathrm{CI}] 4.8-17.0$ ), and an incidence of ADRs leading to admission to a paediatric hospital of $1.8 \%$ (95\% CI $0.4-3.2)$ [12]. Similar findings were observed in a recently published comprehensive review that analysed a total of 102 studies [13].

Greater figures of ADR incidence were estimated in a review of 33 studies monitoring ADRs in general paediatric populations between 1973 and 2009, but this may be due to differences in the design and methods of the included studies [14].

Many drugs used to treat children are either not licensed for, unlicensed, or are prescribed outside the terms of the product license, or "off-label" $[15,16]$. It is likely that the use of unlicensed or "off label" drug prescriptions is associated with a greater risk of ADRs in the paediatric population $[17,18]$.

Few studies are available monitoring the incidence of ADRs in Italian hospitalized children, and some methodological differences do not allow the comparison between the estimates [19-21].

Given the impact of ADRs on morbidity and mortality rates and the potential vulnerability of children to ADRs it is important to evaluate the incidence and nature of ADRs in this population. The aim of this study was to assess: 1) the incidence and common types of ADRs; 2) the drug classes most frequently involved in ADRs among patients aged 0 - 18 years old hospitalized in five general hospitals of the Campania Region, Italy, using a common and simple approach in the general daily clinical practice, and checking for previous or during hospitalization drug exposure related to ADR.

\section{MATERIALS AND METHODS}

Between June and December 2008, a 6-month prospective observational study was carried out on the paediatric wards of five hospitals in a close area of the Campania Region (AORN A. Cardarelli, Naples; PO S. Paolo, Naples; PO S. Maria delle Grazie, Pozzuoli-Naples; PO S. Leonardo, Castellammare di Stabia, Naples; and PO Fatebenefratelli, Benevento). Campania is a geographically and administratively well-defined Mediterranean area located on the west coast of southern Italy.
The five selected hospitals are community hospitals serving different catchment areas, and some are referral centres for the entire paediatric population of Campania, encompassing several different paediatric specialties. The study involved children and adolescents aged 0 to 18 years who were hospitalized in the general paediatric wards of the five hospitals. Parents were informed about the objectives of the study and informed consent for the use of data for research purposes was obtained.

Data were collected by study monitors in two fixed index days of the week, for a total of 48 days, using a standardized data collection form. The form consisted of two parts: the first part concerned individual data (age, gender, weight) and data regarding medication taken during the four weeks preceding hospital admission, i.e., indication, dose, route of administration, duration of treatment, prescriber (physician, pharmacist, or self-medication); the second part concerned data related to diagnosis upon admission, drug prescriptions during hospitalization, and the characteristics of any suspected ADR (drug name, dosage, route of administration, indication, dates of beginning and stopping therapy, description of the reaction, and evolution). Data were collected by interviewing the child's mother or a relative and by reviewing the medical records of the patients included in the study.

In the month preceding the beginning of the survey, study monitors (physicians and pharmacists attending a specialization course in pharmacology and not working in the five selected hospitals) underwent an intensive training on the theoretical and practical aspects of pharmacovigilance. All health professionals on each of the wards were informed of the study. During the visit to the wards, monitors registered new patients, interviewed their mothers or relatives to collect data concerning the drug exposure in the four weeks preceding the admission, and reviewed medical charts.

When necessary, additional data were requested from the ward nurses and prescribing physicians in an attempt to obtain further details on drug prescriptions and ADRs occurring during hospitalization.

Patients were excluded from the study if a drug was taken for any reason other than ordinary therapeutic or prophylactic purposes. Forms lacking information about gender, age, or drug exposure in the four weeks preceding the admission and/or during hospitalization were excluded from the study. Diagnoses were classified using the International Classification of Disease 9th revision (ICD-9). Drugs were classified according to the Anatomical Therapeutic Chemical classification (ATC) system. The number and proportion of drugs administered during hospitalization were calculated for each of the most widely used ATC subgroups $(>5 \%)$; some ATC subgroups were also examined using 4th level ATC 
codes. Age groups were defined according to the International Conference on Harmonization (ICH) Topic E11.

According to the World Health Organization (WHO), an ADR was defined as any noxious, unintended or undesired response to a drug that occurs at doses normally used in man for prophylaxis, diagnosis or treatment of disease, or for the modification of physiological function. Drug abuse and intentional or accidental poisoning (overdose) are not included [22].

In this study, severity was classified as follows: mild (bothersome but requiring no change in therapy), moderate (requiring change in therapy, or additional treatment), severe (life-threatening, requiring hospitalization, or causing serious/permanent disability) [22]. ADRs were coded using the WHO Adverse Reaction terminology [22]. The management strategies used for the ADRs were defined as drug withdrawal, dose reduction, additional treatment for ADR, and no change in regimen with no additional treatment. We also evaluated the final outcome of each ADR.

The Naranjo Adverse Drug Reaction Probability Scale was used to assess the causal relationship between the medication and the ADR [23]. The Naranjo scale assigns the likelihood of a drug causing an untoward event.

Probability is assigned as follows: "highly probable", "probable", "possible" or "doubtful". The Naranjo algorithm is easy to use and is widely applied.

The Committee on Clinical Investigation of the Second University of Naples reviewed and approved the study protocol.

\section{RESULTS}

A total of 752 patients (inter-hospital range: 36 - 356 patients), corresponding to $21.5 \%$ of the hospitalized children in participating hospitals during the study period, were enrolled in the study in the chosen index days. The number of patients admitted to each hospital ranged from 350 to 1500 patients.

Table 1 lists the demographic and clinical characteristics of the study population. Of the 752 patients, $55.5 \%$ were boys and $44.5 \%$ girls and the mean age was 3.8 (median: 3) years. The largest age group was children (2 11 years) $(52.1 \%)$, followed by infants (1 month - 2 years) $(40.8 \%)$.

In the four weeks preceding hospitalization, 568 (75.5\%) patients had taken medications, with an average of $2.8( \pm 1.8)$ drugs per patient. Drug use was more frequent in children $(53.3 \%)$ and infants $(39.9 \%)$, and in males $(56.2 \%)$. The most commonly used therapeutic drug classes during this period were antibacterials for systemic use (41.8\%), analgesics (35.4\%), drugs for obstructive airway diseases $(24.2 \%)$, and corticosteroids for systemic use (18.1\%). Of the prescriptions, $68.2 \%$ were made by a family paediatrician, while $10.4 \%$ were used as self-medication, more than half $(5.5 \%)$ involved paracetamol.

The most common cause of admission was non-specific symptoms (e.g. fever, malaise, and shivering) (69.9\%), gastrointestinal system disorders $(66.2 \%)$, respiratory system disorders $(36.7 \%)$, and neurological disorders $(10.4 \%)$.

No patients with cancer, receiving anaesthesia or surgical procedures, or paediatric intensive care patients, were admitted during the study period.

During their hospital stay, 648 patients $(86.2 \%)$ were exposed to one or more drugs (mean, 2.7 drugs; standard deviation [SD] 1.7). Children received a total of 1396 different drug prescriptions.

The average length of hospital stay was 3.9 days (range: 1 - 36 days; median: 3 days) (Table 1).

Table 1. Demographic and clinical characteristics of the hospitalized children.

\begin{tabular}{lcc}
\hline & Number & $\%$ \\
\hline Patients (N.) & 752 & \\
Age, years: mean (median) & $3.8(3)$ & 0.5 \\
newborns ( - 30 days) & 4 & 40.8 \\
infants (1 month - 2 years) & 307 & 52.1 \\
children (2 - 11 years) & 392 & 6.5 \\
adolescents (12 - 18 years) & 49 & 44.5 \\
Gender & 335 & 55.5 \\
females & 417 & \\
males & \multicolumn{2}{c}{$18.5(14)$} \\
Weight, kg: mean (median) & \multicolumn{2}{c}{$3.9(3)$} \\
Length of stay, days mean (median): & \multicolumn{2}{c}{$2.78(86.2)$} \\
N. patients exposed to $\geq 1$ drug & \multicolumn{2}{c}{$1396 / 152$} \\
N. drugs/patient, mean (median): & \multicolumn{2}{c}{} \\
N. of prescriptions/different drugs & & \\
\hline
\end{tabular}


The most commonly prescribed therapeutic drug classes during hospitalization were antibacterials for systemic use $(46.6 \%)$, analgesics $(38.7 \%)$, corticosteroids for systemic use $(23.5 \%)$, and drugs for obstructive airway diseases $(22.4 \%)$ (Table 2).

Paracetamol was the most frequently prescribed drug (19\% of the overall hospital prescriptions in $39 \%$ of children), followed by amoxicillin (10\% of prescriptions and $21 \%$ of children), betamethasone (7\% of prescriptions and $16 \%$ of children), and salbutamol ( $7 \%$ of prescriptions, $14 \%$ of children) (Table 2).

Six ADRs were detected during the hospitalization period, with an overall incidence rate of $0.9 \%(95 \% \mathrm{CI}$ $0.2 \%-1.7 \%)$.

Table 2. Most prescribed drugs to 648 children during hospitalization.

\begin{tabular}{|c|c|c|c|}
\hline Therapeutic class (ATC) & N. children $(\%)$ & Drug & N. of prescriptions $(\%)$ \\
\hline \multirow[t]{8}{*}{ Antibacterials for systemic use (J01) } & $302(46.6)$ & & \\
\hline & & Amoxicillin & $135(42.6)$ \\
\hline & & Amoxicillin + clavulanic acid & $50(15.8)$ \\
\hline & & Clarithromycin & $34(10.7)$ \\
\hline & & Ceftriaxone & $30(9.5)$ \\
\hline & & Cefotaxime & $23(7.3)$ \\
\hline & & Others & $45(14.2)$ \\
\hline & & Total & $317(100)$ \\
\hline \multirow[t]{4}{*}{ Analgesics (N02) } & $251(38.7)$ & & \\
\hline & & Paracetamol & $264(98.9)$ \\
\hline & & Others & $3(1.2)$ \\
\hline & & Total & $267(100)$ \\
\hline \multirow[t]{6}{*}{ Corticosteroids for systemic use (H02) } & $152(23.5)$ & & \\
\hline & & Betamethasone & $104(64.2)$ \\
\hline & & Prednisone & $29(17.9)$ \\
\hline & & Hydrocortisone & $24(14.8)$ \\
\hline & & Others & $5(3.1)$ \\
\hline & & Total & $162(100)$ \\
\hline \multirow[t]{6}{*}{ Drugs for obstructive airway disease (R03) } & $145(22.4)$ & & \\
\hline & & Salbutamol & $91(59.1)$ \\
\hline & & Salbutamol + ipratropium & $30(19.5)$ \\
\hline & & Beclomethasone & $23(14: 9)$ \\
\hline & & Others & $10(6.5)$ \\
\hline & & Total & $154(100)$ \\
\hline \multirow[t]{6}{*}{ Drugs for acid related disorders (A02) } & $77(11.9)$ & & \\
\hline & & Ranitidine & $56(69.1)$ \\
\hline & & Omeprazole & $7(8.6)$ \\
\hline & & Esomeprazole & $4(4.9)$ \\
\hline & & Others & $14(17.3)$ \\
\hline & & Total & $81(100)$ \\
\hline \multirow[t]{4}{*}{ Anti-inflammatory and antirheumatic drugs (M01) } & $72(11.1)$ & & \\
\hline & & Ibuprofen & $73(98.6)$ \\
\hline & & Ketorolac & $1(1.4)$ \\
\hline & & Total & $74(100)$ \\
\hline
\end{tabular}

ATC, Anatomical Therapeutical Classification. 
Four out of six ADRs occurred in female patients.

The incidence of ADRs was slightly higher in females than in males $(1.4 \%, 95 \%$ CI $0 \%-2.7 \%$ versus $0.6 \%, 95 \%$ CI $0 \%-1.3 \%$, respectively). Three children with ADRs had a history of ADRs, but in all cases the suspected drug was different. The characteristics of the ADRs identified are reported in Table 3. The most commonly affected organ system was the skin and appendages $(n=$ 3 ADRs), with urticarial rash $(\mathrm{n}=2)$, and macular exanthema $(n=1)$ as the clinical manifestations. Other ADRs were: transaminase elevation $(\mathrm{n}=1)$, anaphylactic shock $(\mathrm{n}=1)$, and vomiting $(\mathrm{n}=1)$. The ADRs were considered severe in 2 cases, moderate in 3 , and mild in 1 .

According to the Naranjo probability scale, 5 ADRs were probably related and one was possibly related to the suspected drug. In 5 cases the suspected drug therapy was stopped; 3 cases required additional treatment. All ADRs regressed without long-term sequelae.

One 5 year old female was admitted for an ADR: an amoxicillin-induced Stevens-Johnson syndrome. The incidence of ADRs causing hospitalization was $0.2 \%(95 \%$ CI: $0 \%-0.5 \%)$. The ADRs detected in this study were well-known reactions related to the drug in question.

\section{DISCUSSION}

This paper showed the data of a six-month prospective observational study conducted in the general paediatric wards of five hospitals of the Campania Region. An ADR incidence rate of $0.9 \%(n=6)$ was found in children hospitalized in Campania, Southern Italy, and an incidence of ADR leading to hospitalization of $0.2 \%$. All
ADRs were well-known reactions related to each causative drug.

The results regarding the profile of drug use in the four weeks prior to hospitalization were consistent with findings from national and international drug utilization studies [24,25].

In Campania, the overall number of drugs used per patient during hospitalization was $2.72( \pm 1.71)$, which is consistent with the findings of other prospective studies performed in hospital settings in Europe [26-28].

Similarly, the finding that the most frequently prescribed therapeutic drug class during hospitalization was antibacterials for systemic use $(47 \%)$ is consistent with previous studies $[12,13]$. The most frequently used drug classes also reflected the admitting diagnoses on admission (fever, gastrointestinal diseases, and respiratory system disorders).

The fact that nearly 1 out of 5 admitted children received systemic steroids, and in particular betamethasone, should be underlined. The percentage of treated children is greater than that of other studies, but reflects the wide and inappropriate use of betamethasone for upper respiratory tract infections in some Italian regions [25], and was consistent with the percentage of children exposed to this drug in the four weeks preceding admission.

The frequency of antibacterial drug prescriptions is also greater than in other countries, and is also higher than that observed in an Italian paediatric hospital (47\% versus $38 \%$ ) [29]. However, it is reassuring that amoxicillin was the most prescribed drug instead of amoxicillin + clavulanic acid, as seen in studies from other hospitals [29] and in the outpatient population [25].

Table 3. Characteristics of ADRs detected during the monitoring period.

\begin{tabular}{|c|c|c|c|c|c|c|c|c|}
\hline $\begin{array}{l}\text { Age } \\
\text { (years) }\end{array}$ & Sex & $\begin{array}{l}\text { Suspected } \\
\text { drug }\end{array}$ & Indication & Reaction & Severity & Management & $\begin{array}{l}\text { Concurrent } \\
\text { drug therapy }\end{array}$ & $\begin{array}{c}\text { Naranjo ADR } \\
\text { probability scale }\end{array}$ \\
\hline \multirow[t]{2}{*}{9} & $\mathrm{~F}$ & Acyclovir & $\begin{array}{l}\text { Prophylaxis against } \\
\text { VZV }\end{array}$ & Transaminase elevation & Severe & Drug withdrawal & Oxatomide & Probable \\
\hline & & & & & & Additional treatment & & \\
\hline \multirow[t]{2}{*}{14} & $\mathrm{~F}$ & Iomeprol & Diagnostic procedure & Anaphylactic shock & Severe & Drug withdrawal & Oxatomide & Probable \\
\hline & & & & & & Additional treatment & Hydrocortisone & \\
\hline \multirow[t]{2}{*}{11} & $\mathrm{~F}$ & Paracetamol & Fever & Urticaria & Moderate & Drug withdrawal & Betamethasone & Probable \\
\hline & & & & rash & & & & \\
\hline \multirow[t]{2}{*}{5} & M & Ibuprofen & Fever & Urticaria & Moderate & Drug withdrawal & Paracetamol & Probable \\
\hline & & & & rash & & Additional treatment & Amoxicillin & \\
\hline 1 & $\mathrm{~F}$ & Ceftriaxone & Acute bronchitis & Macular exanthema & Moderate & Drug withdrawal & Paracetamol & Probable \\
\hline 8 & $\mathrm{M}$ & Ranitidine & GERD & Vomiting & Mild & No change in therapy & Diaminocillin & Possible \\
\hline
\end{tabular}


As reported previously and observed in analyses of spontaneous reporting data, skin and appendages were the most affected system disorders in our patients, and systemic antibacterials were frequently implicated in suspected ADRs [12-14,30]. However, it should be considered that antibacterials were the most commonly prescribed drugs.

According to the Naranjo probability scale, 6 of the 7 ADRs detected in our study were probably related to the suspected medication. In previous studies, the percentage of ADRs classified as "probable" in paediatric patients accounted for more than $50 \%[12,13]$. Another aspect of our study was the predominance of dose-independent reactions, mainly allergic reactions. These data can be attributed to the wide use of antibiotics and to the skin reactions observed. All the ADRs detected in our study regressed. Three ADRs (43\%) were severe, and the incidence of severe ADRs was slightly higher than reported in previous studies [12-14].

Although we combined interview with parents with chart review, which detects a higher percentage of ADRs than other methods [31], we found a lower rate of ADRs $(0.9 \%)$ with respect to other studies.

In fact, the incidence of ADRs observed in previous prospective studies ranged between $0.6 \%$ - 16.8\% [12,13].

The number of ADRs detected is small, and this may represent a limitation of the study.

The differences in incidence of ADRs may be due to several reasons: e.g. sample size, pattern of diseases, and disease severity among children admitted to hospitals, methods to identify ADRs, length of hospitalization, and drug exposure. The time frame and the methodology used may also have influenced the likelihood to detect an ADR.

Furthermore, many ADRs are often misdiagnosed in the paediatric population because they cannot be distinguished from naturally occurring clinical manifestations of disease.

The number of drugs prescribed to children in our study was slightly lower than in other settings and this may have contributed to the lower incidence of ADRs. However, it is possible that some ADRs were missed during chart review. Studies conducted in various settings suggest an inadequate knowledge of ADRs among physicians, as well as attitudes indicative of a high degree of underreporting [32-34]. Health care professionals may tend to report only certain or serious ADRs because of unawareness that reports of ADRs are only suspected associations. They tend not to report well-known or nonserious ADRs, thus causing a bias due to selective reporting. Finally, health care professionals may be reluctant to report a suspected ADR if a medicine being used is unlicensed or "off-label", because of potential liability issues [34]. Underreporting is more relevant for ADRs in children, and educational intervention for health professional are effective also in setting characterised by an high rate of spontaneous reporting [35].

Because of the low rate of ADRs in the hospitalized children identified in our study compared with previous findings, there is obviously a need to improve the recognition and detection of ADRs in the paediatric population. Accurate identification and reporting of ADRs in children by health care professionals would lead to a more realistic risk/benefit evaluation and toxicity profile in this particularly vulnerable population. Consequently, measures should be taken to ensure the active surveillance of ADRs in children. Paediatricians could be key players in recognizing, evaluating, monitoring, communicating, and documenting ADRs.

\section{REFERENCES}

[1] Lazarou, J., Pomeranz, B.H. and Corey, P.N. (1998) Incidence of adverse drug reactions in hospitalized patients: A meta-analysis of prospective studies. JAMA, 279, 1200-1205. doi:10.1001/jama.279.15.1200

[2] Schneeweiss, S., Hasford, J., Göttler, M., Hoffmann, A., Riethling, A.K. and Avorn, J. (2002) Admissions caused by adverse drug events to internal medicine and emergency departments in hospitals: A longitudinal population-based study. European Journal of Clinical Pharmacology, 58, 285-291. doi:10.1007/s00228-002-0467-0

[3] Temple, M.E., Robinson, R.F., Miller, J.C., Hayes, J.R. and Nahata, M.C. (2004) Frequency and preventability of adverse drug reactions in paediatric patients. Drug Safety, 27, 819-829 doi:10.2165/00002018-200427110-00005

[4] Moore, T.J., Weiss, S.R., Kaplan, S. and Blaisdell, C.J. (2002) Reported adverse drug events in infants and children under 2 years of age. Pediatrics, 110, e53. doi:10.1542/peds.110.5.e53

[5] Le, J., Nguyen, T., Law, A.V. and Hodding, J. (2006) Adverse drug reactions among children over a 10 -year period. Pediatrics, 118, 555-562. doi:10.1542/peds.2005-2429

[6] Boots, I., Sukhai, R.N., Klein, R.H., Holl, R.A., Wit, J.M., Cohen, A.F. and Burggraaf, J. (2007) Stimulation programs for pediatric drug research-Do children really benefit? European Journal of Pediatrics, 166, 849-855. doi:10.1007/s00431-006-0381-z

[7] Hoppu, K. (2008) Paediatric clinical pharmacology: At the beginning of a new era. European Journal of Clinical Pharmacology, 64, 201-205. doi:10.1007/s00228-007-0390-5

[8] Titchen, T., Cranswick, N. and Beggs, S. (2005) Adverse drug reactions to nonsteroidal anti-inflammatory drugs, COX-2 inhibitors and paracetamol in a paediatric hospital. British Journal of Clinical Pharmacology, 59, 718-723 doi:10.1111/j.1365-2125.2005.02444.x

[9] Clarkson, A. and Choonara, I. (2002) Surveillance for fatal suspected adverse drug reactions in the UK. Archives of Disease in Childhood, 87, 462-466. 
doi:10.1136/adc.87.6.462

[10] Ward, M.R. (1997) Reye's syndrome: An update. The Nurse Practitioner, 22, 45-46.

[11] Yis, U., Ozdemir, D., Duman, M. and Unal, N. (2005) Metoclopramide induced dystonia in children: Two case reports. European Journal of Emergency Medicine, 12, 117-119. doi:10.1097/00063110-200506000-00004

[12] Clavenna, A. and Bonati, M. (2009) Adverse drug reactions in childhood: A review of prospective studies and safety alerts. Archives of Disease in Childhood, 94, 724728. doi:10.1136/adc.2008.154377

[13] Smyth, R.M., Gargon, E., Kirkham, J., Cresswell, L., Golder, S., Smyth, R. and Williamson, P. (2012) Adverse drug reactions in children-A systematic review. PLoS One, 7, e24061. doi:10.1371\%2Fjournal.pone.0024061

[14] Aagaard, L., Christensen, A. and Hansen, E.H. (2010) Information about adverse drug reactions reported in children: A qualitative review of empirical studies. British Journal of Clinical Pharmacology, 70, 481-491. doi:10.1111/j.1365-2125.2010.03682.x

[15] Conroy, S., Choonara, I., Impicciatore, P., Mohn, A., Arnell, H., Rane, A., Knoeppel, C., Seyberth, H., Pandolfini, C., Raffaelli, M.P., Rocchi, F., Bonati, M., Jong, G., de Hoog, M. and van den Anker, J. (2000) Survey of unlicensed and off label drug use in paediatric wards in European countries. European Network for drug investigation in children. British Medical Journal, 320, 79-82. doi:10.1136/bmj.320.7227.79

[16] Pandolfini, C. and Bonati, M. (2005) A literature review on off-label drug use in children. European Journal of Pediatrics, 164, 552-558. doi:10.1007/s00431-005-1698-8

[17] Choonara, I. and Conroy, S. (2002) Unlicensed and offlabel drug use in children: Implication for safety. Drug Safety, 2, 1-5. doi:10.2165/00002018-200225010-00001

[18] Neubert, A., Dormann, H., Weiss, J., Egger, T., CriegeeRieck, M., Rascher, W., Brune, K. and Hinz, B. (2004) The impact of unlicensed and off-label drug use on adverse drug reactions in paediatric patients. Drug Safety, 27, 1059-1067. doi:10.2165/00002018-200427130-00006

[19] Impicciatore, P., Mohn, A., Chiarelli, F., Pandolfini, C. and Bonati, M. (2002) Adverse drug reactions to off-label drugs on a paediatric ward: An Italian prospective pilot study. Paediatric Perinatal Drug Therapy, 5, 19-24. doi:10.1185/146300902322125118

[20] Menniti-Ippolito, F., Da Cas, R., Bolli, M. and Capuano, A. (2007) Studio multicentrico sulla sicurezza dei farmaci in pediatria. Quaderni ACP, 14, 98-102.

[21] Menniti-Ippolito, F., Sagliocca, L., Da Cas, R., Saggiomo, G., Di Nardo, R. and Traversa, G. (2001) Niflumic acid and cutaneous reactions in children. Archives of Disease in Childhood, 84, 430-431. doi:10.1136/adc.84.5.430

[22] World Health Organization (2002) International drug monitoring of adverse reaction terminology. The Uppsala Monitoring Centre, Uppsala.

[23] Naranjo, C.A., Busto, U., Sellers, E.M., Sandor, P., Ruiz, I., Roberts, E., Janecek, E., Domecq, C. and Greenblatt, D.J. (1981) A method for estimating the probability of adverse drug reactions. Clinical Pharmacology and Therapeutics, 30, 239-245. doi:10.1038/clpt.1981.154

[24] Clavenna, A. and Bonati, M. (2009) Drug prescriptions to outpatient children: A review of the literature. European Journal of Clinical Pharmacology, 65, 749-755. doi:10.1007/s00228-009-0679-7

[25] Clavenna, A., Berti, A., Gualandi, L., Rossi, E., De Rosa, M. and Bonati, M. (2009) Drug utilisation profile in the Italian paediatric population. European Journal of Pediatrics, 168, 173-180. doi:10.1007/s00431-008-0725-y

[26] Buajordet, I., Wesenberg, F., Brørs, O. and Langslet, A. (2002) Adverse drug events in children during hospitalization and after discharge in a Norwegian university hospital. Acta Paediatrica, 91, 88-94. doi:10.1111/j.1651-2227.2002.tb01647.x

[27] Jonville-Béra, A.P., Giraudeau, B., Blanc, P., Beau-Salinas, F. and Autret-Leca, E. (2002) Frequency of adverse drug reactions in children: A prospective study. British Journal of Clinical Pharmacology, 53, 207-210. doi:10.1046/j.0306-5251.2001.01535.x

[28] Neubert, A., Dormann, H., Weiss, J., Criegee-Rieck, M., Ackermann, A. and Levy, M. (2006) Are computerised monitoring systems of value to improve pharmacovigilance in paediatric patients? European Journal of Clinical Pharmacology, 62, 959-965. doi:10.1007/s00228-006-0197-9

[29] Ciofi, D.A., M.L., Raponi, M., Tozzi, A.E., Ciliento, G., Ceradini, J. and Langiano, T. (2008) Point prevalence study of antibiotic use in a paediatric hospital in Italy. Euro Surveillance, 13, 41.

[30] Star, K., Norén, G.N., Nordin, K. and Edwards, I.R. (2011) Suspected adverse drug reactions reported for children worldwide: An exploratory study using vigibase. Drug Safety, 34, 415-428. doi:10.2165/11587540-000000000-00000

[31] Weiss, J., Krebs, S., Hoffmann, C., Werner, U., Neubert, A., Brune, K. and Rascher, W. (2002) Survey of adverse drug reactions on a pediatric ward: A strategy for early and detailed detection. Pediatrics, 110, 254-257. doi:10.1542/peds.110.2.254

[32] Hasford, J., Goettler, M., Munter, K.H. and Muller-Oerlinghausen, B. (2002) Physicians' knowledge and attitudes regarding the spontaneous reporting system for adverse drug reactions. Journal Clinical Epidemiology, 55, 945-950. doi:10.1016/S0895-4356(02)00450-X

[33] Herdeiro, M.T., Figueiras, A., Polónia, J. and GestalOtero, J.J. (2005) Physicians' attitudes and adverse drug reaction reporting: A case-control study in Portugal. Drug Safety, 28, 825-833. doi:10.2165/00002018-200528090-00007

[34] Figueiras, A., Herdeiro, M.T., Polónia, J. and GestalOtero, J.J. (2006) An educational intervention to improve physician reporting of adverse drug reactions: A cluster-randomized controlled trial. JAMA, 296, 1086-1093. doi:10.1001/jama.296.9.1086

[35] Arencibia, Z.B., Sotomayor, D.N., Mollinedo, N.C., Choonara, I., Manzano, E.F. and Leyva, A.L. (2010) Adverse drug reactions in children in Camagüey Province, Cuba. Archives of Disease in Childhood, 95, 474-477. doi:10.1136/adc.2009.180786 